\title{
THE FIFTH SEMESTER STUDENTS' SENTENCE VARIETIES IN WRITING STORIES AT UIN ALAUDDIN MAKASSAR
}

\author{
Nur Aliyah Nur \\ Universitas Islam Negeri Alauddin Makassar \\ nuraliyahnur@uin-alauddin.ac.id \\ Sofiya Hilmia \\ Universitas Islam Negeri Alauddin Makassar \\ sofiya.hilmia@uin-alauddin.ac.id \\ Muthi'ah \\ Universitas Islam Negeri Alauddin Makassar \\ muthiah.rahim@uin-alauddin.ac.id \\ Multazam Abubakar \\ Universitas Islam Negeri Alauddin Makassar \\ multazam.abubakar@uin-alauddin.ac.id
}

\begin{abstract}
The study aims to describe the students' ability to change the monotonous story to be interesting by using sentence varieties. The researchers used qualitative descriptive method and the subjects were the fifteen fifth semester students of English Education Department at Alauddin State Islamic University of Makassar (UIN Alauddin Makassar), especially PBI 34. Writing test and interview guidelines were used as the research instrument in which the students were asked to rewrite the texts based on the texts given to them and their opinion about sentence varieties used in the story. The findings of students' tests indicated that majority of students used all kind of sentences, while, minority of students used three types sentences in the stories. Two students used all types, except compound sentence in the first story, compound-complex sentence in second story and compound-complex sentence in both of the stories. The findings of students' interview showed that five students felt that the stories which only contained simple sentence were not interesting, four students felt the stories look bored to read, two students felt the stories were monotonous, two students said the stories not better to read, one student felt the stories too easy to read because like child's stories and one student said the stories which contained sentence varieties were comfortable to read by the students in university. In conclusion, the data showed majority of students' used sentence varieties in their stories and majority of students felt boring to read the story which contained simple sentences.
\end{abstract}

Keywords: Sentence varieties, writing, stories

\section{INTRODUCTION}

11 humans have amazing ability to produce an unlimited number of words and messages
by using language. Through language, humans can remember, develop concept, express
what they feel, and explore their ideas. Those are never regardless from conveying the massage, which are usually delivered with the aim of communication. According to Brown and company (1981), there are three systems of communication, namely: speech, writing and gesture.

One of the systems which is the best way to convey the message of humans' communication is writing. It is important because human live around science and technology, to make both of them be 
remembered, we must keep them in immortal way, such as writing all the knowledge as amenities to all generation before or after us. It is supported by Hadith from Umar ibn Abdil Aziz, he asked Abu Bakar ibn Ham to write and compose the Hadith, he said: "Pay attention to the Hadith of the Prophet or his sunnah and write it, because I am afraid it will disappear with the loss of the scholars". Whereas, from Anas bin Malik Radiyallahu Anhu said, Rasulullah Sallallaahu Alaihi Wasallam said, "Tie science with the book". Those are the result of written communication that we have felt in the form of Al-Qur'an and Hadits, science, since the first. (Al-Qaththan, 2004)

Rass (2001) stated that writing is a difficult skill for native speakers and non-native speakers; because writers must be able to write it in multiple issues such as content, organization, purpose, audience, vocabularies and mechanics such as punctuation, spelling, and capitalization. It is also a challenge for students to be a creative writer to maintain the reader attention without losing sight of their end goal. In addition, the writers need to know some styles and varieties in writing in order to make their writing more interesting and entertaining to the readers.

As a matter of fact, the most interesting and entertaining sentences are the sentences used in songs which are known as lyrics. The lyrics are interesting and able to be interest-bearing because they use various kinds of sentences, word choices, and melody. Therefore, the readers or exactly called as listeners can enjoy the lyrics and they are able to maintain their endurance in listening sentence by sentence written in the lyrics or sang by the singers. Like song that can be interestbearing by using melody, writing also can become interest-bearing by using varying the length, rhythm, use different types of sentences, combine short sentence, vary sentence beginning and expand sentences by adding words and phrases.

A sentence is composed by many words that should be mutually supportive, as well as in a paragraph, the sentence to one another should be interrelated. Thus, the varieties of sentences should be combined each other in order to produce such an interesting and amazing paragraph. According to Oshima-Hague (1998), a good writing requires a mixture of four kinds of sentences: simple, compound, complex, and compound-complex. A composition with only short, simple sentences is boring and ineffective, as writing that uses too many compound sentences.

For students, simple sentences are easier to write and read, but complex sentences are also needed in writing. Because easy written for the readers are not ensuring the reader's interest to read the written until the end. If the students cannot keep the reader, their writing is nothing. Therefore, without varying the length, rhythm and structure of sentences the writer will be losing the reader's attention, and interesting.

Based on some facts and data above, the researchers conducted a qualitative descriptive study in order to analyze the students' ability in using sentence varieties in writing story as well as their opinion about it with the following research focus and its description: 


\begin{tabular}{cccc}
\hline No & Focus & \multicolumn{1}{c}{ Focus Description } \\
\hline $\mathbf{1}$ & $\begin{array}{l}\text { Sentence } \\
\text { varieties }\end{array}$ & $\begin{array}{l}\text { Sentence varieties were a condition where the students not only } \\
\text { used the same various sentences but also used other sentences to } \\
\text { make the stories more interesting. While, the students might use } \\
\text { another style such as paraphrasing, using various tenses or other, } \\
\text { depend on their styles. }\end{array}$ \\
& $\begin{array}{c}\text { The use of } \\
\text { sentence variety } \\
\text { in writing. }\end{array}$ & $\begin{array}{l}\text { The purpose of its use and the way how to use: } \\
\text { a. }\end{array}$ & $\begin{array}{l}\text { Short sentence, it shows one idea clearly. To use simple } \\
\text { sentence joined coordinating conjunctions. }\end{array}$ \\
& b. $\begin{array}{l}\text { Using medium-length sentencesallowed space to connected } \\
\text { ideas and add details. It means used compound sentence } \\
\text { which was coordinating conjunction and used complex } \\
\text { sentence which was joined subordinate conjunction. }\end{array}$ \\
& c. $\begin{array}{l}\text { Using long sentence sparingly to emphasized relationships } \\
\text { and to incorporated significant details. It means } \\
\text { usedcompound-complex sentence which was joined using } \\
\text { subordinate conjunction. }\end{array}$ \\
&
\end{tabular}

Based on the description of the focus described above which becomes the core of the study were: (1) the analysis of sentence varieties was an activity that contained a number of activities such as parsing, differentiating, sorting the data that the students did to be classified according to vary sentence; (2) writing various sentences was the skill that mixing variation of idea, felt, and thought, to get a result of creative writing which was not boring to read by the reader. In writing section, the researchers gave two texts that the students must rewrite the text using vary sentences beginning or expanded sentences by adding words and phrases, combination between long sentence, medium sentence and short sentence to produced four sentences; simple sentence, compound sentence, complex sentence, and compoundcomplex sentence, to create sentence variety in their writing.

\section{REVIEW OF LITERATURE}

\section{Previous Related Studies}

A number of researchers had conducted researches related to students' sentence varieties. There are some previous related studies that supported this research. Some of them are presented as follows:

First, Barcroft (2004) conducted a research about Effects of Sentence Writing on Second Language Lexical Acquisition. The subject of his research was 60 participants of second-semester University-level L2 Spanish Students at the University of Illinois at Urbana-Champaign. The objectives of the research are to prove whether the new words in sentences affect L2 lexical acquisition or not, to find out whether sentence writing is able to decrease L2 lexical Acquisition or no, and to find out the effects of sentence writing on both short term and long term. The research findings show that there is an effect of sentence writing on second language lexical acquisition.

Second, Cooks (2004), in his personal journal reflection in graduate school (1996) on being a secondary student in 1986, analyzed qualitatively how one student writes an essay and a rap on the same subject. The subject of his research was Carlton, an African American adolescent and the other students 
Third, Berger (2006) in his journal Transforming Writers through Grammar Study described a two-year approach to grammar instruction in a middle school. Each month is devoted to a specific sentence variation with a small amount of daily class time for drills and writing assignments. The time rime allows students to assimilate the concepts and apply them to their writing.

Fourth, Dean (2008) conducted an observation about Genre Theory: Teaching, Writing and Being" in 2008. This observation taught about Sentence Combining: Building Skills through Reading and Writing. The subject of her observation that was used for her examples was the students in Jake Rees' classes at Lone Peak High School, Highland, Utah.

Fifth, Hadrus (2017) conducted a research about an Analysis of Students' Difficulties in Translating Argumentative Text from Englsh to Indonesian at the Second Grade Students of SMA Negeri 1 Lappariaja Bone Regency. The subject of her research was Second Grade Students of SMA Negeri 1 Lappariaja. The objective of her research was to analyze the students' difficulties to translate argumentative text by linguistic factors and non-linguistic factors. The results were $75 \%$ difficulties in linguistics actors and $66.67 \%$ in non-linguistics factors.

Sixth, Caroline (2002) L in her research "Prosodic Finality and Sentence Type in French", her participant is six native speakers of French that read 10 matched sets of sentences, which included both statements and questions. She stressed her research on those native speakers' perception after reading those 10 matched sets of sentences.

Seventh, Saddler (2008), et all, in their research entitled the Effects of Sentence-Combining the Writing of Fourth-Grade Students with Writing Difficulties is journal of special education. Their participants are 6 students in fourth grade at an urban elementary school in the Northeast who met the following criteria: identified by the school as having a learning disability and showed evidence of weak writing skills.

In conclusion, the similarities among all related studies above are: based on the researchers' research focuses, they focused on sentence and writing, while the differences among those studies with this study are: the researchers analyzed the students sentence varieties and the purpose of the students used it by using qualitative method, but others, focused on the student's disability, tenses and error analysis. Then, they used experiment and treatment to the students to produce a good writing by using sentence-combining.

\section{Some Partinent Idea}

\section{Concept of Writing}

Walton (1971) stated that "Writing is composed of various portions including the audience, the purpose, and the method or style." According to Sukirman (2014) "Writing is considered as one of the important skills in English that should be taught to the students. By writing, students are able to communicate with others easily across place and time using written forms." In addition, Raimes (1983) indicated that writing is an integral part of communication when the other person is not right there in front of us, listening to our words and looking at our gestures and facial expressions." Therefore, it can 
be said that writing is a way of exploring and sharing information, thoughts, or ideas with using media such like result of work, poetry, story, article, or journal, etc that developed on the basis of ideas, thoughts, information, and observations.

There are other definitions proposed. Byrne (1997) stated that writing is the use of graphic symbols which are arranged according a certain conventions to form words and sentences. In addition to the definitions above, he stated that writing is not merely the act of arranging graphic symbols; he stated that in writing people produce a sequence of sentences arranged in a particular order and linked together in a certain ways. From the statement, it can be said that writingwork follows a gradual stages from a simple use of graphic symbols to a complex arrangement of sentences based on certain rules and conventions. This is supported by Scrivener (1994) who was stated that writing work in the classroom falls on a continuum from copying which focuses on accuracy to free writing which concentrates on fluency.

From previous elaborations it can be concluded that writing is the act of expressing ideas or thoughts in communication using graphic symbols which are arranged based on certain rules and conventions.

\section{Sentence}

General components which had said by Heaton (1988) was using in a sentence. A sentence is a group of words that humans use to communicate their ideas. Basically, there are four kinds of sentences in English: simple, compound, complex, and compound-complex. The kinds of sentences are determined by the kinds of clauses used to form it. According to Oshima-Hague (1998), a good writing requires a mixture of alI four kinds of sentences: simple, compound, complex. and compound-complex.

\section{a) Simple Sentence}

According to Butler (2007) in Fundamentals in Academic Writing book, he stated that simple sentence has one subject-verb combination. So, simple sentence is one independent clause for example: "She has returned to the university".

\section{b) Compound sentence}

According to Wishon and Burks (1980), compound sentence is a sentence that is related to each other in meaning may be combined by using connectors that indicate the relationship between the two sentences. So, to make compound sentence, we need to connect two simple sentences, for example: "She has returned to the university and enrolled herself to psychology class".

\section{c) Complex sentence}

Rizkayadi (2014) stated that complex sentence is two sentences or more that contain of independent and dependent clause. So, it contains one independent clause and one (or more) dependent clause(s), for example: "She has returned to the university when the summer has ended". 


\section{d) Compound-complex sentence}

According to Oshima-Hague (1998), compound-complex sentence is a combination of two or more independent clauses and one (or more) dependent clauses. Many combinations are possible, and their punctuation requires careful attention, for example: "She has returned to the university and enrolled herself to psychology class when the summer has ended".

\section{Concept of Grammar}

After defining sentence, another important concept which must be understood is grammar. Grammar supports the sentence become variety of sentences and produces four sentences. According to Langan (2003), "Standard English, or "language by the book," is needed to communicate humans thoughts to others with a minimal amount of distortion and misinterpretation. Knowing the traditional rules of grammar, punctuation, and usage will help you write clear sentences when communicating with others.

\section{a) Conjunction}

\section{Coordinating Conjunction}

Sukirman (2014) explained coordinating conjunction and function of coordinating conjunction as following: For has function to connect a reason to a result, And to connect equal similar ideas, Nor can be used to connect two negative sentences, But to connect different ideas, Or to connect two equal choice, Yet to connect equal contrasting ideas, another is So to connect a result to a reason.

\section{Paired Conjunctions (Correlative conjunctions)}

Kaharuddin and Latif (2017) stated that Paired Conjunctions (Correlative conjunctions) are known as conjunction which works in pairs to join words, phrases that carry equal position in terms of length and grammatical structure within a sentence.

\section{Subordinating}

Wishon and Burks (1980) explained kind of subordinating conjunction and function of that: the first is When, whenever, while, since, after, before, until, and as which show time of the event, next is where, wherever which refer to place, then is as, as if which explain of manner, after that is as, than which show comparison, next is as, because, so that, in order that, for fear that, since which explain of reason, cause and purpose, next is so ... that, such ... that ... such that which refer of result, then is if, whether, unless, provided (that), on condition that, as/ so long as, supposing (that) which show condition, and finally is although, though, even though, no matter if, while, even if, wherever, whenever, whatever, as much as, whereas which refer to contrast.

\section{b) Punctuation}

Punctuation is used to make the writing uniform. In Writing and Spelling Strategies: Assisting students who have additional learning support needs. NSW Book (2007) stated that punctuation is the practice or system of marking text to help readers' understanding. The use of punctuation is to produce variety sentence by using transition signals. 


\section{c) Sentence Variety}

Wishon and Burks (1980) stated that "Sentence variety is achieved in many ways. Although there are only five to eight basic sentence patterns in English (depending on how general or specific one's categories are), the ways in which to expand and combine them as well as to vary their order is infinite. Sentence length and structure can be varied, as well as the arrangement of sentence parts and the ways in which simple sentence can be combined."

Therefore, sentence variety is combination of four sentences' types to produce an interesting writing by varied sentence in writing. According to Owens Community College Writing Center (2010), there are 3 various length of sentences within the body of a paragraph; (a) Short Sentences present one idea clearly. However, a few well-placed short sentences can add emphasis. (b) Medium sentences allow space to connect ideas and add details, while remaining clear and easy to read. Medium-length sentences are the most versatile and should form the core of writing. (c) Long Sentences establish complex interrelationships and include substantial amounts of amplification and clarification. Use them sparingly to emphasize relationships and to incorporate significant details.

\section{METHOD}

\section{Research Method}

The study used descriptive method with qualitative approach or in brief it was qualitative descriptive study as the data were presented qualitatively in the form of description of the analysis results of students' sentence varieties in writing stories. The study was conducted at UIN Alauddin Makassar.

\section{Research Subject}

The researchers selected the fifth semester students of English Education Department of Tarbiyah and Teacher Training Faculty of UIN Alauddin Makassar. The researchers purposively selected fifteen students from the total number of 39 students PBI 3-4 as the respondents of this study by considering the terms of criteria that were needed by the researchers in this study, those are: (1) the students have taken grammar and writing classes, and (2) the students were in fifth semester when researchers conducted this study.

\section{Research Instrument}

In this study, the researchers used writing test and interview guidelines as the instruments. The writing test is used to ask the students rewrite the text given to them in this case in the form of short story in order to analyze their ability in making sentence varieties, and the interview guidelines were used to investigate the students' perception on the sentences used in the story being given and written.

\section{Data Analysis Technique}

To analyze the students' texts and interview results, the researchers used content analysis to analyze sentence by sentence of the stories. The researchers follow the procedures of data analysis based 
on Miles and Huberman (2014) that suggest qualitative data analysis consists of three procedures: Data Condensation, Data display, and Conclusion drawing and verification.

\section{FINDINGS AND DISCUSSIONS}

\section{Findings}

\section{Students' Sentence Varieties in Writing Stories}

Based on the analysis, the researchers found that there was 1 student used full or complete sentence variety in the first story and second story, there were 3 students used four sentence varieties in second story (simple, compound, complex, and compound-complex sentence), there were nine students which used four sentence variety(simple, compound, complex, and compound-complex sentence) in both of stories, there were 15 students which used simple sentence in both of stories, while there were 2 students used all sentences (simple, complex, and compound-complex sentence) except compound sentence in the first story, two students used three sentence varieties (simple, compound, and complex) except compound-complex sentence in second story and two students used three sentence varieties (simple, compound, and complex) except compound-complex sentence in both of the stores.

As a result, most of the students used four sentences to change the monotonous story, especially complex sentence and compound-complex sentence and less of them more used simple sentence although they still combine with compound, complex, and compound-complex sentence.

The majority of them used simple sentence to change the monotonous story to be better, but a view of them still used more sentence variety. In order to be clear, the researcher would like to discuss a number of simple sentences, compound sentence, complex sentence, and compound complex sentence of the students. Another paraphrased the stories to be clear and simple to read. The important thing was the students would make the stories different to read.

\section{The Result of Students Interview}

Based on the students' interview, the researchers found the following data:

1. There were five students who said the stories which only contained simple sentence were not interesting to read by the reader.

2. There were four students who said the stories which only contained simple sentence were bored to read.

3. There were two students who said the stories which only contained simple sentence were monotonous to read.

4. There were two students who said the stories which only contained simple sentence were not clear to read, so they changed to be varieties and paraphrase.

5. There was one student who said the stories which only contained simple sentence were too easy to read like childhood story.

6. There was one student who said the stories which contained sentence varieties were comfortable to read by the students in university. 
The implications of the data above:

1. Majority of students felt that used simple sentence from the first to end in the stories look monotonous.

2. The students thought that the stories look too bored to read for the reader if only used simple sentence or the same sentence in all paragraph.

3. Some students said the stories look too monotonous to read and like child's stories if only used simple sentence in all story.

4. Another said, the stories were not interesting for the reader if only continued with the same types of sentences, so the students paraphrased the stories to make the stories clearer to read.

5. The students felt the stories which only contained simple sentence were too easy to read and looked like child's stories.

6. Based on students' interview result, the stories were better to read and understand for students in university if not only used simple sentence but also other sentences' types. So, the reader will always curious to read until the end if the story has variety structure of sentence.

\section{Discussion}

Some students still used simple sentence as a style in their stories. Because a simple sentence is very easy to recognize and to this level the structure of simple sentence is understandable by the students without structural confusions, but a composition with only short, simple sentences is boring and ineffective, as is writing that uses too many compound sentences

As a result, all sentences became a complement for each other. Too much a sentence with the same structure could make the writing monotonous, so the writing could be better if the students used variation of sentences in their writing to make the reader interest with what the students were written.

Then, some students used compound sentence to connected two main ideas. The purpose of it was to show another sentence which made the stories more variety. While, some students used complex sentence, they used coordinate conjunction to create this type. Next students chose compound-complex sentence to create another type by the aim of making their stories interesting.

Other students not only used variation of sentences but also paraphrasing the stories. By paraphrasing the students made the stories going on the contents of the stories. So, the reader could understand what the story goal by feeling happiness and not bored to read the stories.

Those findings are in line with Oshima-Hague (1998) point of view that a good writing requires a mixture of all four kinds of sentences: simple, compound, complex. and compound-complex. Therefore, in order to make interesting passages to the readers, the writer needs to combine all those kinds of sentences and create the harmony among those sentences like the harmony of melody, rhythm, lyrics and instruments used in a song. 


\section{CONCLUSION}

The result of test showed majority of students used all kind of sentences. While, minority of students used three types sentences in the stories. The students' used all types, except compound sentence in the first story, compound-complex sentence in second story and compound-complex sentence in both of the stories.

The result of interview showed that generally, the students from English Education Department at UIN Alauddin Makassar thought that stories which only contained simple sentence look bored to read, because like child's stories. Some students put conjunction to produce complex sentence and compound sentence to make an interesting story, other paraphrase the story to make the story clear. The data showed majority of students' used sentence varieties in their stories and majority of students felt boring to read the story which contained simple sentences.

\section{REFERENCES}

Al-Qaththan, S. M. (2005). Pengantar Studi Ilmu Hadits. Pustaka Al Kautsar.

Barcroft, J. (2004). Effects of sentence writing in second language lexical acquisition. Second Language Research, 20(4), 303-334.

Berger, J. (2006). Transforming writers through grammar study. English Journal, 53-59.

Butler, Linda. (2007). Fundamentals of Academic Writing. 10 Bank Street, White Plains, NY: Pearson Education.

Byrne, D. (1979). Teaching writing skills. Longman.

Cooks, J. A. (2004). Writing for something: Essays, raps, and writing preferences. English Journal, 7276.

Corbetta, P. (2003). Social research: Theory, methods and techniques. Sage.

Crane, L. B., Yeager, E., \& Whitman, R. L. (1981). An introduction to linguistics. Little, Brown.

Dean, D. (2008). Sentence combining: Building skills through reading and writing. Classroom notes plus, 26, 6-11.

Hadrus, M. S. (2017). The Analysis of students Difficulties in Translating Argumentative Text from Englih to Indonesian (Doctoral dissertation, Universitas Islam Negeri Makassar).

Heaton, J.B. Writing English Language Tests. New York: Longman, Inc., 1988

Kaharuddin, A., \& Ismail, L. (2017). The Essential of Discourse Analysis. Yogyakarta: TrustMedia Publishing.

Langan, John. (2003). Sentence skills, form B a Work Book for Writers. Seventh ed. America New York: McGraw Hill.

McMillan, J. H. (1996). Educational research: Fundamentals for the consumer. HarperCollins College Publishers, 10 East 53rd Street, New York, NY 10022; World Wide Web: http://www. harpercollins. com/college. 
Miles, M. B., Huberman, A. M., \& Saldana, J. (2014). Qualitative data analysis: A methods sourcebook.

Oshima, A., \& Hogue, A. (2006). Writing Academic English (No. 808.042082 2006). Pearson Education.

Raimes, A. (1983). Techniques in teaching writing. Oxford University Press, 200 Madison Ave., New York, NY 10016 (ISBN-0-19-434131-3, \$5.95).

Rass, R. A. (2001, January). Integrating reading and writing for effective language teaching. In English Teaching Forum (Vol. 39, No. 1, pp. 1-5).

Rizkayadi. (2014). Basic Grammar in your hand. Cet. Ke-1. Jakarta: Yayasan YAPMA.

Saddler, B., Behforooz, B., \& Asaro, K. (2008). The effects of sentence-combining instruction on the writing of fourth-grade students with writing difficulties. The Journal of Special Education, 42(2), 79-90.

Schools, N. P. (2007). Writing and Spelling Strategies: Assisting students who have additional learning support needs.

Scrivener, Jim. (1994). Learning teaching: A guidebook for English Language Teachers. Macmillan Heinemann.

Smith, C. L. (2002). Prosodic finality and sentence type in French. Language and Speech, 45(2), 141178.

Sukirman. (2014). Top Techniques in the Teaching of Writing. $1^{\text {st }}$ ed. Makassar: Alauddin University Press.

Walton, Sam M. (1871). Sentence Variety. University of Arkansas.

Wishon, George E. and Julia M. Burks. (1980). Let's Write English. Revised ed.; New York: Litton Educational. Publishing International. 